\title{
CHRONIC TOXICITY OF A MIXTURE OF CHLORINATED ALKANES AND ALKENES IN ICR MICE
}

\author{
Fun-In Wang
}

Department of Veterinary Medicine, College of Agriculture, National Taiwan University, Taipei, Taiwan

\section{Min-Liang Kuo}

Institute of Toxicology, College of Medicine, National Taiwan University, Taipei, Taiwan

\section{Chia-Tung Shun}

Department of Forensic Medicine, College of Medicine, National Taiwan University, Taipei, Taiwan

\section{Yee-Chung Ma}

Institute of Environmental Health, College of Public Health, National Taiwan University, Taipei, Taiwan

\section{Jung-Der Wang}

Institute of Occupational Medicine and Industrial Hygiene, College of Public Health, National Taiwan University, Taipei, Taiwan

\section{Tzuu-Huei Ueng}

Institute of Toxicology, College of Medicine, National Taiwan University, Taipei, Taiwan

The aim of this study was to determine the chronic toxicity of a mixture of chlorinated alkanes and alkenes (CA) consisting of chloroform, 1,1 -dichloroethane, 1,1-dichloroethylene, 1,1,1 -trichloroethane, trichloroethylene, and tetrachloroethylene. These chlorinated organic solvents were present in the underground water near an electronic appliances manufactory in Taoyuan, Taiwan. Male and female weanling ICR mice were treated with low-, medium-, and high-dose CA mixtures in drinking water for 16 and 18 mo, respectively. A significant number of male mice treated with the high-dose CA mixture developed tail alopecia and deformation, which was not prominent in CA-treated female mice. Medium- and high-dose CA mixtures induced marginal increases of liver and lung weights, blood urea nitrogen, and serum creatinine levels in male mice. In female mice, the high-dose CA mixture increased liver, kidney, and uterus and ovary total weights, without affecting serum biochemistry parameters. CA mixtures had no effects on the total glutathione content or the level of glutathione S-transferase activity in the livers and kid-

The authors thank $\mathrm{Yi}$-Ru Chen, $\mathrm{Yi}$-Jing $\mathrm{Wu}$, and Fung-Lin Liu for their technical assistance. This work was supported by grants EPA-88-G1-04-03-405 and TYEPB-1999-3-RCA-1 from the Environmental Protection Administration, Republic of China.

Address correspondence to Tzuu-Huei Ueng, PhD, Institute of Toxicology, College of Medicine, National Taiwan University, 1 Jen Ai Road, Section 1, Taipei, Taiwan. E-mail: thueng@ ha.mc.ntu.edu.tw 
neys of male and female mice. Treatments with CA mixtures produced a trend of increasing frequency of hepatocelluar neoplasms in male mice, compared to male and female controls and CA-treated female mice. The high-dose CA mixture induced a significantly higher incidence of mammary adenocarcinoma in female mice. The calculated odds ratios of mammary adenocarcinoma in female mice induced by low-, medium-, and high-dose CA mixtures were 1.14, 1.37, and 3.53 times that of the controls, respectively. The lowdose CA mixture induced a higher incidence of cysts and inflammation in and around the ovaries. This study has demonstrated that the CA mixture is a potential carcinogen to male and female mice. These animal toxicology data may be important in assessing the health effects of individuals exposed to the CA mixture.

Chlorinated organic solvents contaminate underground water as a consequence of chlorination during water treatment or illegal deposition and dumping. Chemical analysis of the underground water near a manufactory of electronic appliances in Taoyuan, Taiwan, revealed the presence of chlorinated alkanes and alkenes (CA) including chloroform, 1,1-dichloroethane (DCA), 1,1-dichloroethylene (DCE), 1,1,1-trichloroethane (TCA), trichloroethylene (TCE), and tetrachloroethylene (PCE) (EPA, R.O.C., 1994). The concentrations of many $\mathrm{CA}$ in the underground water were markedly higher than the $5 \mu \mathrm{g} / \mathrm{ml}$ regulatory standard. For instance, TCE and PCE reached 87 and $211 \mu \mathrm{g} / \mathrm{ml}$, respectively, in the water of wells near the factory (Table 1).

In rodents, chlorinated hydrocarbons show systemic toxicity of the liver, kidney, and central nervous system (Snyder \& Andrews, 1996). Multiple organ sites are susceptible to the carcinogenic effects of chlorinated hydrocarbons. Chronic treatment with DCE induced hemangiosarcoma in female CD-1 mice and mammary gland tumors in female Sprague-Dawley rats (Chu \& Milman, 1981). TCE produced tumors in male Swiss mouse liver and lungs (Bruning \& Bolt, 2000). In humans, acute exposure to TCE resulted in temporal loss of movement and sense, hypersensitivity, loss of taste, and irreversible kidney damage (Bruning et al., 1998). An epidemiology study indicated that women exposed to PCE-contaminated drinking

TABLE 1. Concentrations $(\mu \mathrm{g} / \mathrm{ml})$ of Chlorinated Alkanes and Alkenes (CA) in CA Mixtures and Underground Water Near an Electronic Appliances Factory

\begin{tabular}{lcccc}
\hline & \multicolumn{3}{c}{ CA mixture } & \\
\cline { 2 - 3 } Component & Low & Medium & High & $\begin{array}{l}\text { Underground } \\
\text { water }\end{array}$ \\
\hline Chloroform & 5.8 & 7.6 & 14.0 & n.d.-3.0 \\
1,1-Dichloroethane (DCA) & 5.8 & 12.8 & 41.3 & n.d.-36.1 \\
1,1-Dichloroethylene (DCE) & 1.2 & 4.1 & 10.6 & n.d.-82.4 \\
1,1,1-Trichloroethane (TCA) & 2.0 & 3.4 & 119 & n.d.-10.1 \\
Trichloroethylene (TCE) & 44.1 & 106.0 & 471.2 & n.d.-87.0 \\
Tetrachloroethene (PCE) & 36.0 & 90.3 & 606.5 & n.d.-210.6 \\
\hline
\end{tabular}

Note. The concentrations of component compounds in the underground water represent the results of GC/MS analysis of water samples from 20 wells near a manufacturer of electric appliances in Taoyuan, Taiwan (EPA R.O.C., 1994). n.d., Not detectable. 
water showed an increased risk of breast cancer, particularly during the postmenopausal years (Aschengrau et al., 1998). A major mechanism of CA toxicity involves metabolic activation of the chlorinated hydrocarbons to reactive intermediates. Glutathione and glutathione $S$-transferase play an important metabolic role in the tumorigenicity of halogenated alkenes after long-term administration (Dekant \& Henschler, 1999). Cytochrome P-450 (P-450)-dependent monooxygenases are the primary enzyme system responsible for oxidative metabolism of CA. Among the multiplicity of P-450 enzymes, CYP2E1 is involved in metabolic activation of TCE to chloral hydrate (Lash et al., 2000).

Toxicology and risk assessment studies of chemical mixtures have received increasing attention because in reality most environmental contaminants exist as a mixture of compounds, instead of single entities (Calabrese, 1995; Feron et al., 1998). Chlorinated hydrocarbons represent a major complex mixture of underground water contaminants (Yang \& Rauckman, 1987). The aim of this study was to determine the chronic toxicity of a CA mixture in which concentrations of the chlorinated hydrocarbons were similar to those in the underground water near the electronics factory site in Taoyuan. This study may provide hazard identification data important for health risk assessment of the CA mixture.

\section{METHODS}

\section{Animal Treatments}

Male and female weanling ICR mice were purchased from the Animal Center of the College of Medicine, National Taiwan University, Taipei, Taiwan. Before the experiments, mice underwent 1-wk acclimation in quarters with air conditioning and an automatically controlled photoperiod of $12 \mathrm{~h}$ daily. The mice were fed rodent laboratory chow (Purina Mills, Inc., St. Louis, MO) ad libitum and were housed six per cage in plastic shoebox cages with sawdust bedding (PWI Hardwood Sawdust, Lowville, NY). Reagent-grade chloroform, DCA, DCE, TCA, TCE, and PCE were obtained from Sigma Chemical Co. (St. Louis, MO).

Male and female mice were treated with low-, medium-, and highdose CA mixtures in drinking water for 16 and 18 mo, respectively. Table 1 shows the average concentrations of the CA compounds in drinking water determined using gas chromatography-mass spectrometry on $d 1,4$, and 7 after preparation of CA mixtures. In view of the physical and chemical properties of these volatile organic CA compounds, fresh CA mixture was prepared and fed to mice on a weekly basis and glassware was used in CA mixture preparation and feeding procedures.

\section{Enzyme Assays}

Blood from individual mouse was collected using a sterile Vacutainer tube containing SST gel and clot activator (Beckton Dickinson Vacutainer 
Systems, Franklin Lakes, NJ) and centrifuged at $2500 \mathrm{rpm}$ for $10 \mathrm{~min}$. The resulting serum was kept at $4{ }^{\circ} \mathrm{C}$ overnight before serum biochemistry analysis. Liver and kidney were homogenized and the resulting homogenates were subjected to differential centrifugation to prepare cytosols. The homogenates and cytosols were kept at $-70^{\circ} \mathrm{C}$ until enzyme assays within 2 wk. Sera, tissue homogenates, and cytosols from two animals within the same treatment group were pooled when the sample volume from an individual mouse was insufficient for the respective enzyme assays.

Serum enzymes and other biochemical parameters of the controls and mice treated with CA mixtures were determined using a model 7450 automatic autoanalyzer system from Hitachi Ltd., Tokyo, as described previously (Ueng et al., 1998). The total glutathione content of tissue homogenate was determined with the enzymatic recycling assay based on glutathione reductase following the method of Tietze (1969). The cytosolic glutathione $S$ transferase activity toward 1,2-dichloro-4-nitrobenzene was determined following the spectrophotometric method of Habig et al. (1974). The protein concentration was determined by the method of Lowry et al. (1951) using bovine serum albumin as a standard.

\section{Pathology}

Necropsy specimens were fixed in $10 \%$ neutral buffered formalin, embedded in paraffin, sectioned at $5 \mu \mathrm{m}$, and stained with hematoxylin and eosin. Sections of tissues evaluated routinely included the liver, kidney, lungs, heart, testis, ovary, uterus, vagina, esophagus, stomach, small and large intestines, and cecum. Because cystic endometrial hyperplasia is a common aged lesion in mice and leukocytes normally infiltrate the endometrium in different stages of the estrus cycle, which can be judged from the histology of vaginal and uterine mucosa (Jacoby \& Fox, 1984; Turusov et al., 1994; Maekawa \& Maita, 1996), only those lesions considered above the baseline were recorded. Similar criteria applied to lesions in and around the ovaries (McEntee, 1990; Sass \& Rehm, 1994). Histologic typings of hepatocellular, mammary, and lung neoplasms were done according to the criteria used by Frith et al. (1994), Rehm and Liebelt (1996), and Rittinghausen et al. (1996), respectively.

\section{Statistical Analysis}

The significance $(p<.05)$ of the difference between the control and CAtreated group was evaluated by analysis of variance (ANOVA) and Student's $t$-test, utilizing the least-square means of the general linear model procedure (SAS System, SAS Institute, Inc., Cary, NC).

\section{RESULTS}

The untreated and CA mixture-treated male mice showed a mortality rate ranging from $43 \%$ to $47 \%$ at 16 mo (Table 2 ). Therefore, the chronic treatment of male mice was terminated at this point. In female mice, the 
TABLE 2. Effects of Chronic Treatments with CA Mixture on the Mortality Rate of Male and Female ICR Mice

\begin{tabular}{lllll}
\hline & & \multicolumn{3}{c}{ CA mixture } \\
\cline { 4 - 4 } & Control & Low & Medium & High \\
\hline Male & & & & \\
$\quad$ Total number of animals & 40 & 33 & 33 & 43 \\
Number of animals survived & 23 & 18 & 18 & 47 \\
Mortality (\%) & 43 & 45 & 45 & 41 \\
Female & & & & 26 \\
Total number of animals & 36 & 37 & 38 & 37 \\
Number of animals survived & 24 & 28 & 23 & 39 \\
Mortality (\%) & 33 & 24 & 39 & \\
\hline
\end{tabular}

Note. Male and female ICR mice were fed CA mixture in drinking water at the indicated doses for 16 and $18 \mathrm{mo}$, respectively.

control and CA-treated groups showed a mortality rate ranging from $24 \%$ to $39 \%$ at 18 mo. Cage-side observations revealed that $34 \%$ of male mice treated with the high-dose CA mixture had tail alopecia and deformations such as rings and wrinkles, compared to the respective $20 \%$ tail alopecia and $2 \%$ tail deformations in the controls.

Treatment of male mice with the high-dose CA mixture caused a $10 \%$ increase in liver weight; treatment with the medium-dose CA mixture caused $25 \%$ and $37 \%$ increases in lung weight and lung to body weight ratio, respectively (Table 3 ). CA mixtures did not cause significant changes in body, liver, or kidney weights in male mice. Treatment of female mice with the high-dose CA mixture caused $21 \%, 11 \%$, and $17 \%$ increases in liver weight, liver to body weight ratio, and kidney weight, respectively, as well as a two-fold increase in the uterus and ovary total weight. The lowand medium-dose CA mixtures produced a trend of increase in the uterus and ovary total weight and tissue to body weight ratio; however, the differences were not statistically significant. Treatments with CA mixtures had no effects on body weight, liver, kidney, or lung weights or on tissue to body weight ratios in female mice.

In male mice, the levels of blood urea nitrogen (BUN) and creatinine (CRE) in CA mixture-treated groups showed a trend of dose-dependent increase; however, only the levels of the medium-dose CA mixture-treated group were significantly higher than their respective controls (Table 4). The levels of alanine aminotransferase (ALT), aspartate aminotransferase (AST), $\gamma$ glutamyltransferase $(\gamma \mathrm{GT})$, and lactate dehydrogenase $(\mathrm{LDH})$ in CA-treated mice were similar to the respective controls. In female mice, the CA mixtures caused a trend of dose-dependent increases of serum ALT and AST levels, and the high-dose CA mixture produced a $45 \%$ increase of $\gamma$ GT level; however, the differences were not statistically significant. The CA mixtures 
TABLE 3. Effects of Chronic Treatments with CA Mixture on the Body and Tissue Weights in Male and Female ICR Mice

CA mixture

\begin{tabular}{|c|c|c|c|c|}
\hline & \multirow[b]{2}{*}{ Control } & \multicolumn{3}{|c|}{ CA mixture } \\
\hline & & Low & Medium & High \\
\hline Male & $(n=23)$ & $(n=18)$ & $(n=18)$ & $(n=23)$ \\
\hline Body weight, g & $48.9 \pm 1.0$ & $50.7 \pm 1.4$ & $45.5 \pm 1.57$ & $50.7 \pm 1.0$ \\
\hline Liver weight, g & $2.78 \pm 0.08$ & $2.80 \pm 0.10$ & $2.75 \pm 0.24$ & $3.05 \pm 0.09^{a}$ \\
\hline Liver/body weight $\times 100, \mathrm{~g} / \mathrm{g}$ & $5.68 \pm 0.11$ & $5.60 \pm 0.23$ & $5.98 \pm 0.42$ & $6.03 \pm 0.14$ \\
\hline Kidney weight, g & $1.10 \pm 0.03$ & $1.10 \pm 0.04$ & $1.01 \pm 0.04$ & $1.15 \pm 0.05$ \\
\hline Kidney/body weight $\times 100, \mathrm{~g} / \mathrm{g}$ & $2.25 \pm 0.06$ & $2.20 \pm 0.06$ & $2.23 \pm 0.07$ & $2.28 \pm 0.08$ \\
\hline Lung weight, g & $0.32 \pm 0.01$ & $0.30 \pm 0.03$ & $0.40 \pm 0.04^{a}$ & $0.35 \pm 0.01$ \\
\hline Lung/body weight $\times 100, \mathrm{~g} / \mathrm{g}$ & $0.67 \pm 0.03$ & $0.70 \pm 0.09$ & $0.92 \pm 0.11^{a}$ & $0.69 \pm 0.03$ \\
\hline Female & $(n=24)$ & $(n=28)$ & $(n=23)$ & $(n=26)$ \\
\hline Body weight, g & $40.3 \pm 1.4$ & $41.0 \pm 1.5$ & $42.3 \pm 1.4$ & $43.5 \pm 1.4$ \\
\hline Liver weight, $g$ & $2.03 \pm 0.09$ & $2.04 \pm 0.08$ & $2.22 \pm 0.10$ & $2.45 \pm 0.12^{a}$ \\
\hline Liver/body weight $\times 100, \mathrm{~g} / \mathrm{g}$ & $5.04 \pm 0.16$ & $4.97 \pm 0.09$ & $5.24 \pm 0.14$ & $5.59 \pm 0.16^{a}$ \\
\hline Kidney weight, g & $0.58 \pm 0.02$ & $0.59 \pm 0.02$ & $0.66 \pm 0.07$ & $0.68 \pm 0.03^{a}$ \\
\hline Kidney/body weight $\times 100, \mathrm{~g} / \mathrm{g}$ & $1.44 \pm 0.04$ & $1.46 \pm 0.03$ & $1.55 \pm 0.11$ & $1.56 \pm 0.05$ \\
\hline Lung weight, g & $0.35 \pm 0.03$ & $0.37 \pm 0.03$ & $0.34 \pm 0.02$ & $0.34 \pm 0.02$ \\
\hline Lung/body weight $\times 100, \mathrm{~g} / \mathrm{g}$ & $090 \pm 0.08$ & $0.94 \pm 0.09$ & $0.83 \pm 0.06$ & $0.79 \pm 0.04$ \\
\hline Uterus and ovary weight, $g$ & $0.51 \pm 0.03$ & $0.79 \pm 0.13$ & $1.22 \pm 0.57$ & $1.02 \pm 0.22^{a}$ \\
\hline Uterus and ovary/body weight $\times 100, \mathrm{~g} / \mathrm{g}$ & $1.30 \pm 0.12$ & $1.96 \pm 0.33$ & $2.64 \pm 1.02$ & $2.35 \pm 0.51$ \\
\hline
\end{tabular}

Note. Male and female ICR mice were fed CA mixture in drinking water at the indicated doses for 16 and 18 mo, respectively. Each value represents the mean \pm SE in each group.

${ }^{a}$ Value significantly different from the respective control, $p<.05$.

had no effects on the BUN or CRE levels in female mice. Further studies were carried out to analyze the metabolic activation systems for chlorinated hydrocarbons in liver and kidney. In both male and female mice, no significant changes of the total glutathione content and cytosolic glutathione $S$ transferase activity were observed in the livers and kidneys (Table 5).

In male mice, the CA mixture-treated groups showed a general trend of higher incidence of hepatocellular neoplasms (HN) as compared to the untreated males and females and CA-treated females (Table 6 and Figure 1). Histologically, hepatocellular adenomas were predominantly a basophilic type sometimes mixed with few vacuolated cells. Hepatocellular carcinomas were predominantly a well-differentiated trabecular type, and some carcinomas apparently "arose within adenoma." There were also sporadic incidences of aging lesions including multifocal testicular atrophy and mineralization, Leydig-cell adenomas predominantly of the undifferentiated type and occasionally carcinomas, bronchioloalveolar adenomas and carcinomas, and miscellaneous mesenchymal tumors (lymphomas, hemagiosarcomas, fibrosarcoma, leiomyosarcomas, and a few undifferentiated sarcomas); however, the differences between the control and treated groups were not significant. 
In female mice, the high-dose CA mixture induced a higher frequency of mammary adenocarcinomas (MA) (Table 7). Grossly, MA present as subcutaneous masses distributed primarily in the abdominal-inguinal and occasionally in the chest and anal areas of the mice (Figure 2). Masses of MA were well circumscribed, pale, fleshy, and oval to nodular in shape, ranging from 0.5 to $2.0 \mathrm{~cm}$ in diameter, with occasional red discoloration presumably caused by hemorrhage and/or necrosis. Histologically, most MA were predominantly a mixture of acinar (Figure 3), tubular, papillary, and solid patterns (formerly type B), and a few MA were pure acinar type with cytoplasmic vacuoles and secretory activity (formerly type A) or adenomyoepithelioma (formerly type $\mathrm{C}$ ). The calculated odd ratios of female mice treated with low-, medium-, and high-dose CA mixtures showing MA were $1.14,1.37$, and 3.53 times that of the controls (normalized to 1), respectively.

In some CA mixture-treated female mice, the uterus showed unilateral or bilateral diffuse endometrial hyperplasia together with luminal dilatation (Figure 4; Maekawa \& Maita, 1996), up to $5 \mathrm{~cm}$ (from the cervix to the end of horn) $\times 3 \mathrm{~mm}$, while the normal size of uterus usually measured only 2 $3.5 \mathrm{~cm} \times 1-2 \mathrm{~mm}$. Some uteri simply had endometrial hyperplasia without luminal dilatation. Histologically, a thickened mucosa containing hyperplastic and occasionally cystically dilated uterine glands (Figure 4, as seen grossly) with hyperplastic stroma was observed. Although these lesions

TABLE 4. Effects of Chronic Treatments with CA Mixture on the Serum Biochemistry Parameters in Male and Female ICR Mice

CA mixture

Control

Low

Medium

High

\begin{tabular}{lcccc}
\hline Male & $(n=12)$ & $(n=9)$ & $(n=10)$ & $(n=11)$ \\
Alanine aminotransferase, U/L & $107.0 \pm 13.0$ & $138.0 \pm 28.0$ & $117.0 \pm 32.0$ & $94.0 \pm 14.0$ \\
Aspartate aminotransferase, $\mathrm{U} / \mathrm{L}$ & $223.0 \pm 15.0$ & $242.0 \pm 14.0$ & $231.0 \pm 17.0$ & $212.0 \pm 15.0$ \\
$\gamma$-Glutamyltranspeptidase, $\mathrm{U} / \mathrm{L}$ & $7.0 \pm 0.0$ & $6.0 \pm 0.0$ & $7.0 \pm 0.0$ & $9.0 \pm 1.0$ \\
Lactate dehydrogenase, $\mathrm{U} / \mathrm{L}$ & $1436.0 \pm 97.0$ & $1559.0 \pm 62.0$ & $1447.0 \pm 113.0$ & $1425.0 \pm 115.0$ \\
Blood urea nitrogen, $\mathrm{mg} / \mathrm{dl}$ & $28.7 \pm 1.2$ & $32.9 \pm 2.8$ & $46.0 \pm 7.4^{a}$ & $72.5 \pm 32.2$ \\
Creatinine, mg/dl & $0.3 \pm 0.0$ & $0.4 \pm 0.0$ & $0.6 \pm 0.1^{a}$ & $1.1 \pm 0.6$ \\
Female & $(n=13)$ & $(n=8)$ & $(n=15)$ & $(n=19)$ \\
Alanine aminotransferase, U/L & $48.0 \pm 4.0$ & $52.0 \pm 4.0$ & $64.0 \pm 9.0$ & $88.0 \pm 27.0$ \\
Aspartate aminotransferase, U/L & $185.0 \pm 8.0$ & $200.0 \pm 10.0$ & $229.0 \pm 40.0$ & $263.0 \pm 56.0$ \\
$\gamma$-Glutamyltranspeptidase, U/L & $6.5 \pm 0.2$ & $6.4 \pm 0.2$ & $6.9 \pm 0.8$ & $9.4 \pm 2.9$ \\
Lactate dehydrogenase, U/L & $1174.0 \pm 86.0$ & $1317.0 \pm 86.0$ & $1260.0 \pm 138.0$ & $1167.0 \pm 124.0$ \\
Blood urea nitrogen, $\mathrm{mg} / \mathrm{dl}$ & $26.8 \pm 0.7$ & $28.9 \pm 0.8$ & $34.8 \pm 7.9$ & $27.1 \pm 1.1$ \\
Creatinine, mg/dl & $0.4 \pm 00$ & $0.4 \pm 0.0$ & $0.4 \pm 0.0$ & $0.4 \pm 0.0$ \\
\hline
\end{tabular}

Note. Male and female ICR mice were fed CA mixture in drinking water for 16 and 18 mo, respectively. Sera from two animals within the same treatment group were pooled when the serum volume of individual mouse was insufficient for serum biochemistry analysis. Each value represents mean \pm SE for the number of samples indicated in the parentheses.

${ }^{a}$ Value significantly different from the respective control, $p<.05$. 
TABLE 5. Effects of Chronic Treatments with CA Mixture on the Total Glutathione Content and Glutathione S-Transferase Activity in Male and Female ICR Mice

CA mixture

\begin{tabular}{|c|c|c|c|c|}
\hline & \multirow[b]{2}{*}{ Control } & \multicolumn{3}{|c|}{ CA mixture } \\
\hline & & Low & Medium & High \\
\hline \multicolumn{5}{|l|}{ Male } \\
\hline Liver & $(n=14)$ & $(n=14)$ & $(n=14)$ & $(n=14)$ \\
\hline Glutathione ( $\mu \mathrm{mol} /$ liver) & $4.56 \pm 0.27$ & $4.78 \pm 0.24$ & $4.66 \pm 0.29$ & $4.84 \pm 0.33$ \\
\hline $\begin{array}{l}\text { Glutathione } S \text {-transferase } \\
(\mu \mathrm{mol} D N P G / \mathrm{min} / \mathrm{mg} \text { protein })\end{array}$ & $2.57 \pm 0.12$ & $2.42 \pm 0.08$ & $2.44 \pm 0.07$ & $2.60 \pm 0.09$ \\
\hline Kidney & $(n=8)$ & $(n=9)$ & $(n=7)$ & $(n=8)$ \\
\hline Glutathione ( $\mu$ mol/kidney) & $1.27 \pm 0.10$ & $1.38 \pm 0.06$ & $1.29 \pm 0.05$ & $1.34 \pm 0.06$ \\
\hline $\begin{array}{l}\text { Glutathione } S \text {-transferase } \\
(\mu \mathrm{mol} \mathrm{DNPG} / \mathrm{min} / \mathrm{mg} \text { protein })\end{array}$ & $0.58 \pm 0.02$ & $0.60 \pm 0.01$ & $0.53 \pm 0.02$ & $0.59 \pm 0.01$ \\
\hline \multicolumn{5}{|l|}{ Female } \\
\hline Liver & $(n=14)$ & $(n=14)$ & $(n=14)$ & $(n=14)$ \\
\hline Glutathione ( $\mu \mathrm{mol} /$ liver $)$ & $4.56 \pm 0.27$ & $4.78 \pm 0.24$ & $4.66 \pm 0.29$ & $4.84 \pm 0.33$ \\
\hline $\begin{array}{l}\text { Glutathione } S \text {-transferase } \\
(\mu \mathrm{mol} \mathrm{DNPG} / \mathrm{min} / \mathrm{mg} \text { protein })\end{array}$ & $2.57 \pm 0.12$ & $2.42 \pm 0.08$ & $2.44 \pm 0.07$ & $2.60 \pm 0.09$ \\
\hline Kidney & $(n=8)$ & $(n=9)$ & $(\mathrm{n}=7)$ & $(n=8)$ \\
\hline Glutathione ( $\mu$ mol/kidney) & $1.27 \pm 0.10$ & $1.38 \pm 0.06$ & $1.29 \pm 0.05$ & $1.34 \pm 0.06$ \\
\hline $\begin{array}{l}\text { Glutathione } S \text {-transferase } \\
(\mu \mathrm{mol} \mathrm{DNPG} / \mathrm{min} / \mathrm{mg} \text { protein })\end{array}$ & $0.58 \pm 0.02$ & $0.60 \pm 0.01$ & $0.53 \pm 0.02$ & $0.59 \pm 0.01$ \\
\hline
\end{tabular}

Note. Male and female ICR mice were fed CA mixture in drinking water for 16 and 18 mo, respectively. Tissue homogenates and cytosols from two mice were pooled when the homogenate or cytosol sample volume was insufficient for assays. The total glutathione content and glutathione $S$ transferase activity were determined as described in Methods.

${ }^{a}$ Each value represents mean \pm SE for the number of samples indicated in the parentheses.

were considered age related, they were not impressive in control females in this study.

Female mice treated with low- and high-dose CA mixtures showed a trend of increases in the frequency of cystic endometrium and uterine inflammation. however the increases were not statistically significant (Table 7). Female mice treated with low-dose CA mixture also had a higher frequency of ovarian cysts and inflammation. The high-dose CA mixture also showed a similar high frequency but the difference was not significant. The ovarian cysts were primarily epoophoron and paroophoron, measured up to $0.7-2 \mathrm{~cm}$ in diameter, either solitary or multiple, usually filled with a clear transparent fluid and occasionally blood clot (hematocysts). The normal ovaries usually were $1-2 \mathrm{~mm}$ in diameter. Histologically, the ovarian cysts were lined by ciliated lining epithelium with surrounding smooth muscle fibers, and usually associated with atrophy of adjacent parenchyma. The endometrial hyperplasia and various ovarian cysts and inflammation were consistent with the increased uterus and ovary weight shown in Table 3. Other tumors observed in female mice were similar to those described in male mice. 
TABLE 6. Effects of Chronic Treatments with CA Mixture on Hepatocellular Tumorigenicity in Male and Female ICR Mice

\begin{tabular}{lllll}
\hline & & \multicolumn{3}{c}{ CA mixture } \\
\cline { 3 - 4 } & Control & Low & Medium & High \\
\hline Male & $1(n=23)$ & $3(n=18)$ & $4^{a}(n=15)^{b}$ & $1(n=23)$ \\
Female & $0(n=24)$ & $0(n=28)$ & $0(n=22)^{c}$ & $0(n=25)^{c}$ \\
\hline
\end{tabular}

Note. Male and female ICR mice were fed CA mixture in drinking water for 16 and 18 mo, respectively. The number of animals in each group is indicated in the parentheses.

${ }^{a}$ Value significantly different from the controls, $p<.05$.

${ }^{b}$ Three mice had liver missing during processing were not included.

${ }^{c}$ One mouse had liver missing during processing was not included.

\section{DISCUSSION}

The present findings demonstrate that chronic treatment with CA mixture has the ability to promote the occurrence of $M A$ and $H N$ in ICR mice. $\mathrm{MA}$ and $\mathrm{HN}$ are considered common aging lesions for female and male mice, respectively (Frith et al., 1994; Rehm \& Liebelt, 1996). The spontaneous incidences of MA and $\mathrm{HN}$ in control female and male mice were $0 \%$ and $4.3 \%$, respectively, in this study (Tables 6 and 7 ), which

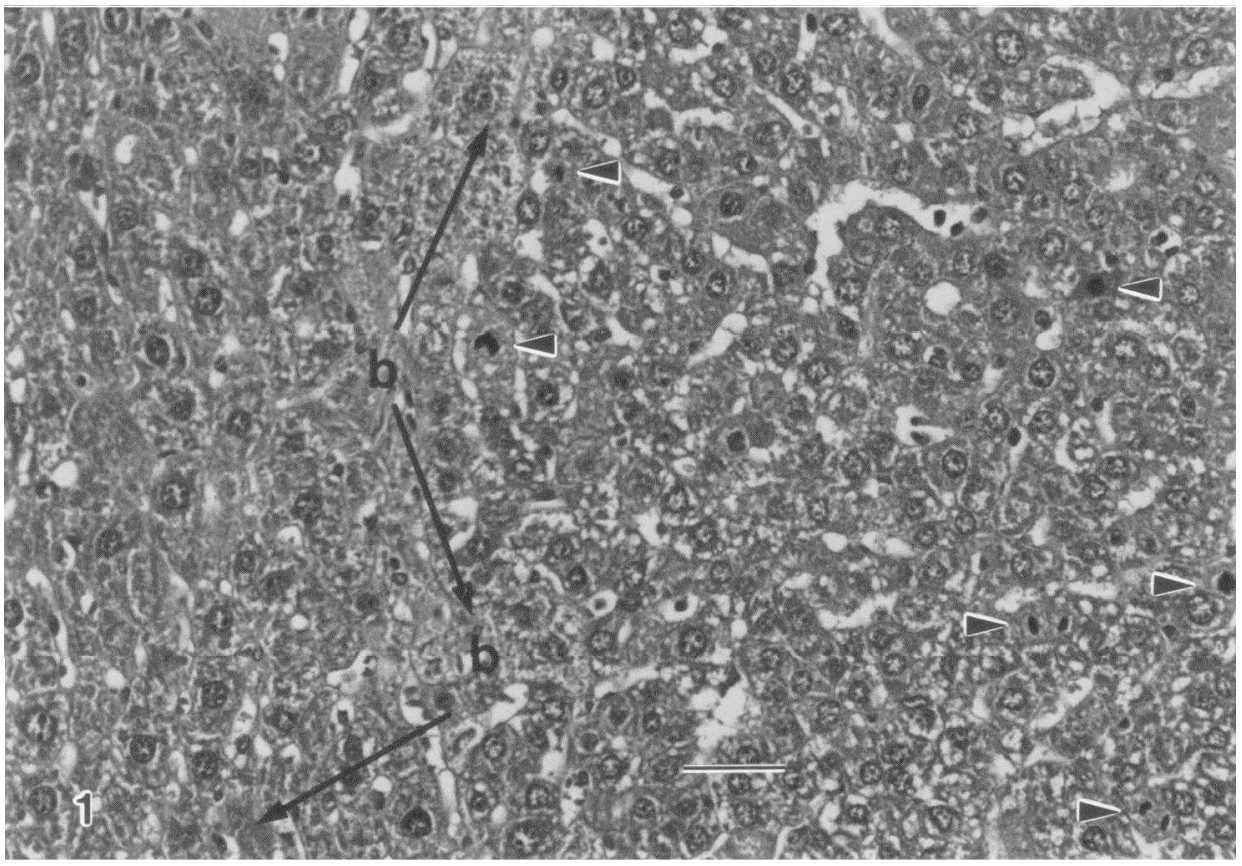

FIGURE 1. A basophilic hepatocellular adenoma with prominent mitotic figures (arrowheads) that form a nodule (upper and lower right) bordering (b) adjacent normal hepatocytes (left) in an ICR male mouse treated with the medium-dose CA mixture. Bar $=37 \mu \mathrm{m}$. 
TABLE 7. Effects of Chronic Treatments with CA Mixture on Mammary Adenocarcinoma and the Reproductive System of Female ICR Mice

\begin{tabular}{|c|c|c|c|c|}
\hline & \multirow[b]{2}{*}{$\begin{array}{l}\text { Control } \\
(n=24)\end{array}$} & \multicolumn{3}{|c|}{ CA mixture } \\
\hline & & $\begin{array}{l}\text { Low } \\
(n=28)\end{array}$ & $\begin{array}{l}\text { Medium } \\
(n=23)\end{array}$ & $\begin{array}{l}\text { High } \\
(n=26)\end{array}$ \\
\hline \multicolumn{5}{|l|}{ Mammary gland } \\
\hline Adenocarcinoma & 0 & 1 & 0 & $5^{e}$ \\
\hline \multicolumn{5}{|l|}{ Uterus } \\
\hline Cyst $^{a}$ & 2 & 6 & 3 & 7 \\
\hline Inflammation ${ }^{b}$ & 0 & 3 & 0 & 0 \\
\hline \multicolumn{5}{|l|}{ Ovary } \\
\hline Cyst $^{c}$ & 3 & 11 & 2 & 6 \\
\hline Inflammation $^{d}$ & 0 & 1 & 0 & 1 \\
\hline
\end{tabular}

Note. Female ICR mice were fed CA mixture in drinking water for $18 \mathrm{mo}$. The number of animals in each group is indicated in the parentheses.

${ }^{a}$ Cystic endometrium.

${ }^{b}$ Endometritis, pyometra, metritis, uterine abscess, parametritis, and/or perisalpingitis.

${ }^{c}$ Predominantly parovarian cysts and/or occasionally rete cyst and hematocyst.

${ }^{d}$ Periovaritis.

${ }^{e}$ Value significantly different from the control, $p<.05$.

were slightly lower than the spontaneous incidences of $1.6 \%$ and $9.6 \%$ in related female and male ICR mice in 18-mo studies reported elsewhere (Charles River, 1987). However, the present data showed that CA mixturetreated female and male ICR mice had statistically significant higher incidences of $\mathrm{MA}$ and $\mathrm{HN}$, compared to their respective control animals, in 16to 18-mo studies. Thus, these data strongly suggest that the CA mixture produced a promotional effect in increasing the incidences of aging lesions $M A$ and $H N$ in ICR mice.

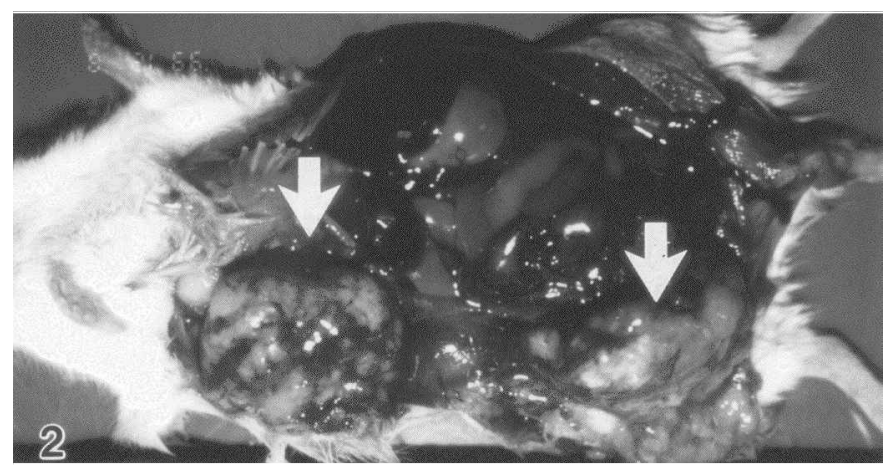

FIGURE 2. Mammary adenocarcinomas characterized grossly as pale, fleshy, nodular, well-circumscribed masses are present in the neck (left arrow) and inguinal (right arrow) areas of an ICR female mouse treated with the high-dose CA mixture. 


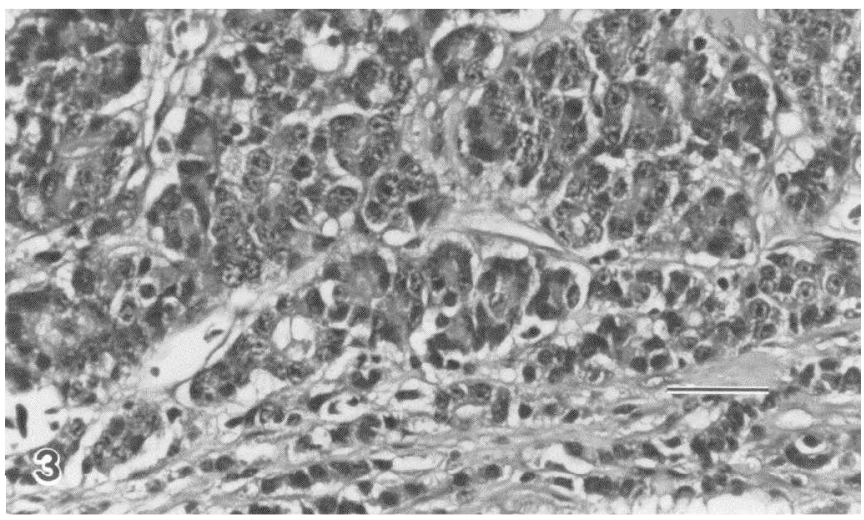

FIGURE 3. Mammary adenocarcinomas, containing predominantly acinar pattern in this case, are present more frequently in female ICR mice treated with the CA mixture. Bar $=74 \mu \mathrm{m}$.

This chronic toxicity study of CA mixture reveals pronounced sex differences. The female mice showed a greater mammary carcinogenicity and a longer life span, while the male mice showed a greater hepatocellular tumorigenicity and a more frequent tail abnormality. The higher frequency of tail abnormality in CA mixture-treated male mice might be hormone related. Male mice treated with low- and medium-dose CA mixtures showed a trend of higher incidence of HN (Table 6), compatible with the understanding that spontaneous $\mathrm{HN}$ in the males are more frequent than in the females in many mouse strains (Frith et al., 1994).

The concentrations of chlorinated hydrocarbons in the CA mixtures were comparable to their respective concentrations in the underground water near a factory producing electronic appliances in Taoyuan, Taiwan.

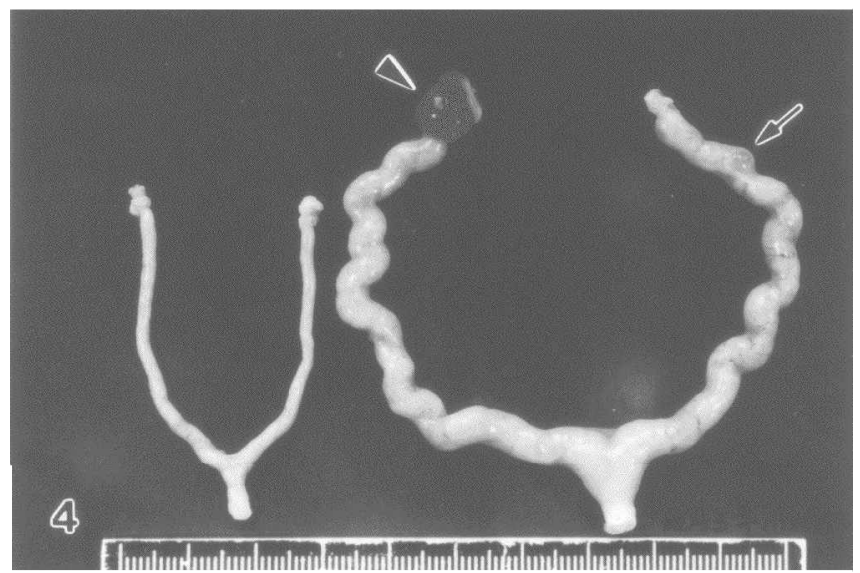

FIGURE 4. Bilateral diffuse endometrial hyperplasia together with luminal dilatation (right) are present more frequently in female ICR mice treated with CA mixture. Notice the cystic endometrium (arrow) and the ovarian cyst (arrowhead). A normal uterus is shown on the left for comparison. 
The toxicological data derived from these environmentally relevant concentrations should allow a reasonable extrapolation of animal toxicology data to human health risk. Previous studies showed that DCE induced rat mammary-gland tumors and DCE, TCE, and PCE induced mouse hepatocellular tumors (Bruning \& Bolt, 2000; Chu \& Milman, 1981). Therefore, these chlorinated hydrocarbons contributed at least partially to the formation of tumors in mice in this study. The present data do not exclude the possibility that other compounds in the mixture and their metabolites might have caused synergistic or antagonistic effects during different stages of systemic toxicity and tumorigenesis. The present data showed that chronic treatment with CA mixture had no effect on the total glutathione content and glutathione $S$-transferase activity (Table 5). The CA mixture did not alter P-450 content or CYP2E1-dependent aniline hydroxylase activity in liver and kidney microsomes (data not shown). This lack of effects on the glutathione $S$-transferase- and P-450-mediated pathways suggests that these metabolic enzymes played limited roles in the later stages of chronic toxicity of CA mixture, among other possibilities.

The increases in liver and kidney weights and BUN and CRE indices (Tables 3 and 4) in CA mixture-treated mice are in general agreement with the characteristic hepatotoxicity and renal toxicity of chlorinated hydrocarbons (Snyder \& Andrews, 1996). However, the increases in organ weights, thought to be hypertrophies (Bruning \& Bolt, 2000), could not be readily detected microscopically and biochemically in mice treated with CA mixture. Damage of Clara cells that occurs after the acute or subacute inhalation exposure to chlorinated hydrocarbons (Moser \& Balster, 1985) was not evident in this chronic oral exposure study. The CA-elicited increase in the uterus and ovary total weight (Table 3 ) of female mice was consistent with the endometrial hyperplasia and luminal dilatation (Figure 4) and lesions found in and around the female reproductive system (Table 7). It is not inconceivable that CA mixture acted as an endocrine disruptor and predisposed the female reproductive system to the various diseases found (Table 7). Additional studies are needed to explore this possibility.

The tumorigenic effects of CA mixture did not exhibit the regular dose-response relationships (Tables 6 and 7). This irregularity may be a reflection of the fact that the mice were exposed to a mixture of chemicals whose complex chemical interactions differentially modulated tumorigenicity of CA mixture. In conclusion, the present study shows that the CA mixture induces mammary carcinogenesis in female ICR mice and hepatocelluar tumorigenesis in the male mice. These data emphasize the need to carry out long-term health assessment of humans exposed to the CA mixture.

\section{REFERENCES}

Aschengrau, A. L., Paulu, C., and Ozonoff, D. 1998. Tetrachloroethylene-contaminated drinking water and the risk of breast cancer. Environ. Health Perspect. 106:947-953.

Bruning, T., and Bolt, H. M. 2000. Renal toxicity and carcinogenicity of trichloroethylene: Key results, mechanisms, and controversies. Crit. Rev. Toxicol. 30:253-285. 
Bruning, T., Vamvakas, S., Makropoulos, V., and Birner, G. 1998. Acute intoxication with trichloroethene: clinical symptoms, toxicokinetics, metabolism, and development of biochemical parameter for renal damage. Toxicol. Sci. 41:157-165.

Calabrese, E. J. 1995. Toxicological consequences of multiple chemical interactions: a primer. Toxicology 105:121-135.

Charles River. 1987. Spontaneous neoplastic lesions in the Crl:CD-1® (ICR)BR mouse, 18 months studies.

Chu, K. C., and Milman, H. A. 1981. Review of experimental carcinogenesis by compounds related to vinyl chloride. Environ. Health Perspect. 41:211-220.

Dekant, W., and Henschler, D. 1999. Organ-specific carcinogenicity of haloalkenes mediated by glutathione conjugation. J. Cancer Res. Clin. Oncol. 125:174-181.

Environmental Protection Administration, Republic of China. 1994. A report of survey and measurement of wells in residential areas surrounding an RCA Taoyuan factory [in Chinese]. Taipei, Taiwan: Environmental Protection Administration, Republic of China.

Feron, V. J., Cassee, F. R., and Groten, J. P. 1998. Toxicology of chemical mixtures: International perspective. Environ. Health Perspect. 106:1281-1289.

Frith, C. H., Ward, J. M., and Turusov, V. S . 1994. Tumors of the liver. In Pathology of tumors in laboratory animals, vol. II. Tumors of the mouse, eds. V. S. Turusov and U. Mohr, pp. 223-267. Lyon: IARC Scientific Publication No. 111.

Habig, W. H., Pabst, M. J., and Jakoby, W. B. 1974. Glutathione S-transferase. The first enzymatic step in mercapturic acid formation. J. Biol. Chem. 249:7130-7139.

Jacoby, R. O., and Fox, J. G. 1984. Biology and diseases of mice. In Laboratory animal medicine, eds. J. G. Fox, B. J. Cohen, and F. M. Loew, pp. 31-89, Orlando, FL: Academic Press.

Lash, L. H., Fisher, J. W., Lipscomb, J. C., and Parker, J. C. 2000. Metabolism of trichloroethylene. Environ. Health Perspect. 108:177-200.

Lowry, O. H., Rosebrough, N. J., Farr, A. L., and Randall, R. J. 1951. Protein determination with Folin phenol reagent. J. Biol. Chem. 193:265-275.

Maekawa, A., and Maita, K. 1996. Changes in the uterus and vagina. In Pathology of the aging mouse, vol. 1, eds. U. Mohr, D. L. Dungworth, C. C. Capen, W. W. Carlton, J. P. Sundberg, and J. M. Ward, pp. 469-480. Washington, DC: ILSI Press.

McEntee, K. 1990. Cysts in and around the ovary. In Reproductive pathology of domestic animals, pp. 52-68. San Diego, CA: Academic Press.

Moser, V. C., and Balster, R. L. 1985. Acute motor and lethal effects of inhaled toluene, 1,1,1trichloroethane, halothane and ethanol in mice: Effects of exposure duration. Toxicol. Appl. Pharmacol. 77:285-291.

Rehm, S., and Liebelt, A. G. 1996. Nonneoplastic and neoplastic lesions of the mammary gland. In Pathology of the aging mouse, vol. 2, eds. U. Mohr, D. L. Dungworth, C. C. Capen, W. W. Carlton, J. P. Sundberg, and J. M. Ward, pp. 381-398. Washington, DC: ILSI Press.

Rittinghausen, S., Dungworth, D. L., Ernst, H., and Mohr, U. 1996. Primary pulmonary tumors. In Pathology of the aging mouse, vol. 1, eds. U. Mohr, D. L. Dungworth, C. C. Capen, W. W. Carlton, J. P. Sundberg, and J. M. Ward, pp. 301-314. Washington, DC: ILSI Press.

Sass, B., and Rehm, S. 1994. Tumors of the ovary. In Pathology of tumors in laboratory animals, vol. II, Tumors of the mouse, eds. V. S. Turusov and U. Mohr, pp. 493-526. Lyon: IARC Scientific Publication No. 111.

Snyder, R. S., and Andrews, L. S. 1996. Toxic effects of solvents and vapors. In Casarett \& Doull's toxicology, ed. C. D. Klaassen, 5th ed., pp. 737-771. New York: McGraw-Hill.

Tietze, F. 1969. Enzymatic method for qualitative determination of nanogram amounts of total and oxidized glutathione. Anal. Biochem. 27:502-522.

Turusov, V. S., Munoz, N., and Dunn, T. B. 1994. Tumors of the vagina, uterus and oviduct. In Pathology of tumors in laboratory animals, vol. II, Tumors of the mouse, eds. V. S. Turusov and U. Mohr, pp. 451-491. Lyon: IARC Sci. Pub. No. 111.

Ueng, T.-H., Hwang, W.-P., Chen, R.-M., Wang, H.-W., Kuo, M.-L., Park, S. S., and Guengerich, F. P. 1998. Effects of motorcycle exhaust on cytochrome P-450-dependent monooxygenases and glutathione S-transferase in rat tissues. J. Toxicol. Environ. Health A 54:509-527.

Yang, R. S. H., and Rauckman, E. J. 1987. Toxicological studies of chemical mixtures of environmental concern at the National Toxicology Program: Health effects of groundwater contaminants. Toxicology 47:15-34. 